\title{
Case of Nodular Leprosy, with Massive Enlargement of Cervical and Thyroid Glands.
}

BERNARD MoIser.

DATIENT, named Nyambi, was a well-nourished man of about 20 years when admitted to Ngomahuru. Leprosy Hospital, on October 31st, 1930. A younger
brother was admitted later. Primary lesion had been an ulcer on outer side of left wrist.

The Skin was very nodular all over exterior surfaces, with very little hypopigmentation. Face and ears nodular, scrotum enlarged and thickened, and both testes were nodulated. He spoke in a whisper.

Nerves.-Auriculars, ulnars, and peroneals all thickened and tender.

Anaesthesia.-Extensive in both forearms and hands, outer side of lower extremities from hip down. Cervical and femoral glands enlarged. Tongue nodular, and there. were some smiall ulcers on the palate. Nose and ear both very positive, with large rods. He was classified N3 C3, 
and treated with alepol at that time, later with esters. $\mathrm{He}$ improved for a time and regained his voice.

By early 1932, the cervical glands had become very large, with one or two sinuses discharging yellow pus. This was examined on several occasions for actinomycosis, but none was found. About this time the thyroid gland began to enlarge, and with the cervical glands formed a very large swelling in the neck. General condition remained remarkably good.

He absented himself in February, 1933, without permission, and returned in April, when it was found that he had a syphilitic ulcer, for which he was given a full course of spirobismol and kharsulphan, which cleared up all syphilitic manifestations. The glands in neck and thyroid continued to enlarge, discharging masses of mycobacteria, and the patient died on January 22nd, 1934.

The glandular enlargement was apparently entirely due to leprosy.

The photograph shows the patient's condition on $25 / 5 / 32$, and on $24 / 10 / 33$, and it will be observed that the thyroid did not begin to enlarge until the cervical glands had already assumed very large proportions. Glands in other parts of the body were not enlarged, except the femoral, and these only to a slight extent. 